\title{
ALGUNOS ASPECTOS PRINCIPISTAS DE UN NUEVO DERECHO
}

Las consideraciones que siguen se sitúan dentro del campo de la Filosofía del Derecho, por ello las referencias al Derecho Positivo son mínimas. La finalidad que se pe.sigue es tratar un tema espinoso y difícil como es el correspondiente al llamado "nuevo Derecho", el cual presenta no pocos obstáculos desde que su contenido está dibujándose hace muy poco tiempo. Como en todo terreno científico, este tema no puede abordarse únicamente como una simple reforma de la legislación, sino que se debe buscar las razones principistas que motivan el cambio y que al mismo tiempo han de posibilitar su desarrollo. En base a estas consideraciones es que nos formulamos ciertas preguntas básicas que han de orientar el desarrollo de nuestro estudio. ¿Por qué se habla de un nuevo Derecho?. Si tiene sentido esa expresión, ¿cuáles serían las líneas posibles de su estructuración? $\mathrm{Y}$ volvemos a recordar que estamos ubicados en la perspectiva de la Filosofía del Derecho.

En primer lugar, vamos a detenernos en causas de tipo filosófico; desde luego que ellas no excluyen las motivaciones de tipo científico como los descubrimientos de la sociología o la economía, sino que en cierto modo las suponen, máxime si en nuestra época la Filosofía no puede trabajar sin el conocimiento de los logros de la ciencia positiva.

Para comenzar, es preciso referirse a una tendencia que parece esencial al Derecho: su conservadorismo. Entre las varias finalidades que cumple el Derecho, está la correspondiente a mantener un equilibrio de las relaciones humanas, exento de todo conflicto. Así Kelsen piensa que el Derecho es una técnica de organización social destinada a suprimir los conflictos de intereses. Visto el Derecho desde esta perspectiva, resulta lógico que busque crear en las relaciones humanas un estado permanente de paz social, don- de una ruptura signifique a lo más dos cosas: o bien un estado anormal que la legislación positiva puede reparar (caso de los delitos del Código Penal), o en su defecto que puede ser resuelto pacificamente (caso de beneficios sociales que son reconocidos por un Tribunal del Trabajo, aunque reconozco que este procedimiento no siempre es pacífico...). Así tenemos que el Derecho por su especial finalidad tiende siempre a crear una situación estable y, lógicamente, duradera. ¿Podríamos imaginarnos una sociedad donde su organización jurídica sea inestable, esto es, que no se sepa si dentro de dos días tal o cual acto no sea ya delito castigado por las leyes? Es claro que sería imposible. Pero el desarrollo de la existencia humana y las consiguientes concepciones de la realidad de hoy, han introducido una serie de elementos que chocan contra esta característica, y obligan por lo tanto a una revisión profunda del Derecho, por ello es preciso tomar todo el peso a esta afirmación. pues ella no importa un mero reajuste de ciertos dispositivos de un código o el cambio de una ley por otra, sino que imponen una nueva perspectiva que ha de tener consecuencias hoy en día no vislumbradas.

Hemos hablado de concepción de la realidad. Pensemos por un momento cuál ha sido esta concepción en la cual se apoyaron sistemas jurídicos como el romano, el napoleónico o cualquiera de los llamados clásicos. Era una concepción de la inmovilidad, donde lo permanente se entendía como la verdadera esencia de lo real. En el fondo, estamos hablando de la concepción metafísica que ha partido de Parménides. El Ser es lo que no cambia. Recordemos las primeras formulaciones del Derecho Natural y hallaremos la confirmación: se ha hablado de derechos imprescriptibles e inalienables; se mencionaba una naturaleza propia de las cosas la que no podia ser violada sino 
protegida, asi los derechos humanos (no nos referimos a las "Declaraciones de..." sino a los derechos referibles al hombre). Incluso las estructuras sociales de esas épocas se consideraban inmutables así el llamado "derecho divino de los reyes". Pero en nuestra época este modo de encarar las cosas ha sido objeto de un cambio radical. Por efecto de una clara aceleración del tiempo humano (es imposible detenernos en este punto por su extensión), y por las hipótesis científicas que han resultado más operativas y por tanto más eficaces, la realidad desprende una interpretación dinámica donde lo inmutable resulta imposible gracias a lo cual las formas cambiantes suben a primer plano. La Filosofía pura ha intentado interpretar este giro de perspectiva, sea por el camino del evolucionismo creador o dialéctico (Bergson, Teilhard de Chardin o Marx), o por el dinamismo en sí (caso de Whitehead) o en fin por los actuales intentos del estructuralismo.

Como bien lo señala Foucault, las teorias de cualquier ciencia o conocimiento humano y por lo tanto del Derecho, sólo son posibles dentro de un "zócalo epistemológico" determinado; lógicamente, cambia ese "zócalo" y cambia la concepción científica. En este sentido, sólo podemos pensar ciertas cosas si existen las condiciones de pensamiento necesarias; pongamos por ejemplo, un concepto abscluto de la propiedad ("uso y abuso") es posible dentro de un universo fijo, donde hay substancias permanentes y por ende relaciones entre las substancias igualmente permanentes. Mas dentro de un universo dinámico, donde todo cambia, las relaciones entre las cosas serán igualmente dinámicas y modificables. En el caso de nuestro estudio, creemos que este "zócalo epistemológico" del Derecho ha cambiado de una concepción inmutable a una concepción dinámica y relacionante.

Hemos mencionado la palabra relacionante y ello implica grandes significados. La concepción actual de las cosas agrega una nueva nota a su constitución, pues ellas ya no se definen únicamente por su consistencia sino también, y para muchos únicamente, por las relaciones que tiene con las demás cosas. Volvamos al ejemplo de la propiedad; si hoy queremos definirla no lo podemos hacer exclusivamente por la relación con el titular del derecho (el propietario), sino que debemos recurrir al papel que cumple respecto de los demás hombres, es decir, y comprendo que a muchos esto suene como herejía, el titular del derecho no es una persona sino una estructura de relacio- nes humanas que inciden sobre un bien determinado, donde una tendrá cierta preferencia sobre las demás pero jamás será exclusiva. Este sistema de relaciones no termina aquí, pues el conjunto mismo de relaciones, en cuanto ellas son interactuantes, es capaz de crear una nueva realidad diferente de sus componentes. Un ejemplo simple, una sociedad anónima tiene derechos que no puede tener uno de sus componentes aislados.

Si ahondamos más esta revisión breve de conceptos, llegaremos a uno básico sin el cual el Derecho no tendría sentido alguno: el concepto del hombre. Es preciso reconocer que si hay Derecho es para normar las relaciones humanas. Aquí la pregunta básica: ¿cómo concebimos hoy al hombre?, diciéndolo con más profundidad, ¿cuáles son las concepciones del hombre que laten bajo nuestros sistemas juridicos? Un estudio exhaustivo de este tipo ha de proporcionar innumerables sorpresas. Hay razones para pensar en un "nuevo derecho" pues nuestro concepto de hombre se ha ido enriqueciendo notablemente en nuestros días. Pongamos un caso, las relaciones humanas han tenido un modelo muy claro deniro de las actuales legislaciones de todo el mundo, en la antropovisión liberal donde la voluntad personal, inspirada en la idea de libertad, constituia una fuente de derechos que las leyes sólo podían proteger. Es el caso de los contratos que, como bien dice Friedmann, ya no dependen tanto de la voluntad de las partes sino que van adquiriendo un estatuto cada vez más institucionalizado, pues proviene no de la voluntad individual sino de la voluntad de un grupo. Este es un punto importante de la concepción del hombre actual: tiene una doble vertiente de acción, una como ser individual y otra como perteneciente a un grupo, con el agravante que el grupo cada vez se independiza y gana terreno en una consideración autónoma, como es el caso de los paises socialistas donde el individuo se conecta con el estado a través del sindicato, del koljoz.

Hay todavía otra concepción del hombre que ha de influir en una revisión de los conceptos de Derecho. Como derivado de la concepción dinámica de la realidad, el hombre también aparece como un ser dinámico, pero con una característica fundamental, su dinamismo se traduce en una posibilidad. Es decir, el hombre no surge completo en la realidad sino como una potencia que debe alcanzar su plenitud y a través, como ya vimos, de las relaciones humanas. Es- 
ta consideración vuelve al hombre como muy difícil de encuadrar dentro de una estructura jurídica que tenga una tendencia conservadora que supone más bien una visión estática del hombre.

Las consecuencias de lo ya descrito se van evidenciando poco a poco. Si los supuestos epistemológicos del Derecho están en franca modificación, ello implicará una revisión profunda de las concepciones jurídicas. Desde luego que los estudiosos del Derecho han intentato encarar el problema y los esfuerzos son muchos, por lo cual intentamos una escueta revisión de estos intentos.

Creemos que esos intentos, desde nuestro punto de vista, pueden ser agrupados hasta en tres grupos, desde luego reconociendo que toda clasificación tiene un simple valor didáctico y que es por esencia incompleta. Veamos estos tres grupos:

a) Fundamento Iógico-científico: la ciencia positiva ha intentado lograr una estructura universal de validez y operatividad del conocimiento, que garantice el máximo rigor científico. En gran parte parece haberlo conseguido mediante las estructuras axiomáticosimbólicas que por su carácter puramente formal, tiene el anhelado valor universal. Para muchos autores la revisión o re-estructuración del Derecho tiene en esta metodología (pues fundamentalmente es eso: metodología) la vía de solución. Cabe mencionar en este punto el intento de Kelsen quien sin llegar a una formalización estricta de la ciencia juridica, ha intentado construir una "ciencia pura" significando por tal un saber organizado y sobre todo, desprovisto de implicancias ajenas al Derecho mismo como han sido los supuestos morales. Depurado el Derecho, se procede entonces a una estructuración rígidamente lógica, donde es evidente el modelo axiomático pues se parte de una norma fundamental aceptada por convención o por hipótesis (que puede ser en el Derecho Positivo la Constitución), de la cual se derivarán todas las demás normas jurídicas. ¿Qué concede entonces validez al sistema de derecho? Simplemente la conexión lógica entre las normas particulares y la fundamental. De este modo se evita ligar lo juridico a concepciones del mundo que pudieran tener implicancias ideológicas, esto es, que exigieran respetar una filosofía de corte medieval por ejemplo, o llevar a defender un orden económico determinado. Lo jurídico logra su máxima pureza pero es preciso reconocer que también queda desprovisto de todo contenido concreto. ¿Por qué valdrá una norma legal?
Por un hecho muy simple: por haber sido promulgada siguiendo lo señalado en la llamada norma fundamental. No puede soslayarse el peligro real que trae esta concepción: se cae en un mero positivismo que en el fondo puede justificar cualquier tipo de organización jurídica, una que hasta viole lo más elemental de la persona humana como fueron las leyes de discriminación racial en la Alemania nazi; según este hecho, serian leyes que obligarian por haber sido promulgadas y estar relacionadas con la norma fundamental (pero hipotética) de la concepción nazi. Los resultados ya los conocemos.

Deberiamos mencionar también ciertos intentos de aplicar los resultados de la lógica-matemática, que convierte en cierta manera al Derecho en un sistema del todo formalizado y con perspectivas de reemplazar a los jueces por computadoras electrónicas, pues es sabido que todo sistema de conocimientos capaz de formalizarse puede ser operado por un cerebro de este tipo. Imaginemos un sistema tal: un demandante presenta su escrito a una máquina la cual responde al cabo de diez segundos con una sentencia, que es notificada a otras máquinas para ser ejecutada. Sin hacer funcionar la imaginación de tal manera, consideramos preciso hacer algunas consideraciones sobre los alcances de estos intentos.

Nadie puede negar con seriedad que la formalización lógica ha traído un rigor insustituible al conocimiento, pero que al mismo tiempo precisa de un análisis previo a la aplicación concreta. En el caso del Derecho esta labor resulta fundamental pues si bien este saber tiene una estructura eminentemente axiomática, toda norma juridica sea pura o correspondiente al Derecho positivo, supone ciertos valores que desbordan el campo lógico. En este sentido toda norma tendría dos dimensiones: una, correspondiente al sistema lógico-axiomático pues ella debe encuadrar, efectivamente, dentro de un conjunto normativo mucho más amplio y donde existe una conexión lógica. No podemos pensar, por lo menos en teoría, que en el Perú se den normas desvinculadas de los códigos o la constitución; ese ligamen resulta necesario. Pero al lado de esta propiedad, la norma jurídica supone una segunda relación, esto es, que aparte de su significación lógica posee otra significación que sería de carácter axiológico. Esta situación vuelve a esta norma muy compleja, de tal manera, que la aleja del ideal puramente formal o matemático que sirve de base a la metodología lógica. Podemos afirmar en con- 
clusión que una norma jurídica tiene por lo menos dos aspectos: el axiológico y el lógico. $Y$ creemos que el primero es el fundamental, al que se subordina el segundo que viene a ser metodológico. La razón estriba en que la norma jurídica tiene que referirse (su relación semántica, en términos lógico-matemáticos) a la conducta humana y ésta se realiza por una elección de fines. Cuando el legislador promulga una ley, desea en el fondo que la conducta humana se oriente hacia un tipo específico de comportamiento, el cual articulado con las demás leyes que promulgan lo mismo, llegan a crear un medio humano donde lo jurídico da forma a las diversas conductas. Esta situación lleva a conclusiones importantes en la Filosofía del Derecho, pues en última instancia se está postulando un cierto substancialismo en el contenido de la norma jurídica; efectivamente, si el aspecto lógico aunque necesario no resulta decisivo, la mayor significación queda asignada al contenido axiológico el cual ya señala una consistencia ontológica, que aunque esté referida a una conducta presente o futura, no queda disuelta en simples convencionalismos. Con todo es preciso aclarar que al mencionar el término "substancialismo" no estamos defendiendo en modo alguno ninguna vuelta al aristotelismo, sino señalando tan sólo un finalismo que resulta consistente por sí mismo.

Por todo lo dicho, el procedimiento de fundamentación lógico-científico adquiere una importancia ligada al aspecto de estructuración del sistema jurídico pero que sin embargo no absorbe toda la consistencia del Derecho el cual desborda este aspecto por presentar una densidad ontológica que de ninguna manera es puramente formal. La solución lógica es más que nada metodológica y servirá al nuevo derecho para estructurarse en ciencia, pero no para proporcionar de modo directo los contenidos jurídicos que norman la conducta humana.

b) Convencionalismo jurídico: pese a que parte de este tema ya lo hemos mencionado en los párrafos anteriores, es conveniente completar su consideración. Parte de la influencia de esta doctrina proviene del positivismo jurídico y de la inclusión del Derecho en el ámbito de las ciencias sociales. Quizás resume la tesis fundamental, la frase que sostiene que "el Derecho es una técnica de organización social", la cual antes que buscar valores como la justicia por ejemplo, se limita a evitar los conflictos de intereses. Esta actitud tiene una importancia que es preciso reconocer pues ha liberado al Derecho de las vinculaciones con teorías que sostenían la existencia de normas inmutables, que podian ser determinadas en fórmulas exactas. Estamos hablando de algunas maneras tradicionales de entender el Derecho Natural, donde el punto básico residía en sostener que ciertos derechos eran inmodificables como ha sido durante mucho tiempo la concepción individualista del derecho de propiedad o la no intervención del estado en la libre industria, e incluso el llamado "derecho divino de los reyes". Desde luego que estas concepciones tenian una clara tendencia a estancar el derecho por su creencia de que el orden ideal habia sido ya descubierto. El movimiento que denominamos nosotros como "convencionalismo jurídico" ha permitido romper estas barreras $y$ ha liberado una pluralidad de interpretaciones de lo jurídico que ha sido sumamente eficaz. Por otro lado, ha conseguido una mayor flexibilidad del Derecho que le ha permitido, adaptarse a las cambiantes situaciones sociales, económicas y culturales.

Pero una tal interpretación posee no pocos peligros, pues en el fondo llega a justificar cualquier consideración acerca de los derechos humanos, llegando al relativismo que en materia jurídica es sin lugar a dudas un serio peligro. En el fondo es el extremo opuesto del absolutismo conservador que considera ya establecidos los derechos fundamentales. Creemos que esta posición olvida que el Derecho tiene una relación fundamental con ciertas situaciones humanas, que deben ser normadas según ciertos fines que se van haciendo evidentes con el desarrollo de la historia. Un convencionalismo o positivismo puro tiene que prescindir de este tipo de relación y quedar ligado tan sollo a la voluntad del legislador, la cual bien pronto se volverá insuficiente por un exceso de variabilidad que sólo podrá ocasionar transtornos en la vida social.

Tampoco el Derecho puede reducirse a una mera técnica de organización social. Es este un influjo del positivismo de las ciencias sociales que hoy por hoy es uno de los más peligrosos. Hay una cierta ceguera al creer que los métodos científicos son capaces de producir resultados inmejorables por su sola y simple aplicación. Los problemas se solucionan inmediatamente. Es preciso hacer notar entonces que este prejuicio tecnicista encubre una concepción, conciente o no, de tipo mecanicista o conductista que asemeja las realidades humanas al funcionamiento automático de las computadoras electrónicas. Olvida esta concepción que toda ciencia que trabaja con ob- 
jetos humanos debe tener en cuenta la libre elección que puede hacer un hombre, lo cual implica poder diferir unas respuestas e incluso resistirse a las motivaciones que se le presentan. Claro que algunos podrán hablar de un nuevo concepto de técnica pero en este caso no será nunca el que está en uso en la ciencia actual. Con todo ¿habrá una técnica jurídica inspirada en la naturaleza humana y que por consiguiente las respete? Pero en verdad ésta es una pregunta que no se ha planteado ni el positivismo ni el convencionalismo.

c) Practicismo: existe también otra tendencia a reformar el Derecho que es menos doctrinaria, y que se inspira en las necesidades concretas de la sociedad. No ha elaborado una teoria fundante del Derecho sino que constituye una respuesta inmediata a problemas concretos. Quizás convenga ejemplificar algo esta situación. En la práctica el legislador, no siempre el investigador del derecho, tiene que afrontar situaciones concretas que exigen una reforma de la legislación, así en nuestro medio hemos tenido la Ley de Reforma Agraria, el Código Tributario y el Decreto Ley sobre la Universidad Peruana, todos los cuales presentan reformas promovidas por los problemas que esos sectores ofrecian. Pero aqui surge la cuestión crítica: todas las reformas presentan criterios diferentes, pues mientras unas tienen un claro sentido estatista-socializante, otras representan una cierta transacción entre socialismo y liberalismo, mientras que las demás eligen un camino bastante cientifista. Entonces la concepción unitaria del sistema jurídico se resiente y en muchos casos deja de existir. Aquí la razón de muchas reformas fracasadas, pues una reforma para tener éxito necesita funcionar dentro de un contexto unitario; es fácil comprender que una ley individual para funcionar precisa de conexiones con otras. Un sistema juridico es un todo indivisible y correlacionado, o como se dice en la actualidad, es una estructura. Si falta la unidad, resulta imposible un funcionamiento eficaz. Tal vez esta es la razón oculta del fracaso de muchas reformas en el Perú, pues la reforma aislada es buena pero dentro de un sistema diferente resulta frustrada. Una ley socializante exige un contexto del mismo tipo, de lo contrario no sólo es inoperante sino que se convierte a la larga en motivo de constantes disturbios tanto en la legislación como en las soluciones de los tribunales, que en el fondo no son contradictorias sino que son el reflejo de la falta de unidad del sistema. La organi- zación jurídica de un país debe ser un todo coherente en sus pretensiones $y$ en sus principios.

Es evidente que una renovación del Derecho en función de los problemas actuales no puede seguir este camino, pues en realidad implica una dosis inaceptable de improvisación. Se necesita por el contrario realizar un proceso diferente y mucho más complicado. Es preciso inventariar la problemática del pais con el fin de tener la base empírica que deberá normar la reforma; luego es preciso dar un paso que a muchos investigadores resultará incomprensible pero que exige en el peor de los casos algunas reflexiones previas a la reforma jurídica. Nos estamos refiriendo a la opción ideológica. Aunque muchos pensadores hablan de la independencia de pensamiento, ello en la práctica resulta casi imposible; el mundo está regido en nuestra época por una lucha ideológica que abarca todos los campos y por consiguiente es inevitable encarar el problema; puede ser que no sea preciso llegar a una elección pero si es útil determinar los alcances de cada problema y de cada solución. Hay muchos investigadores que por no hacer esta determinación previa llegan a conclusiones que son simplemente un conglomerado de diversas orientaciones, y ello sin darse cuenta claramente de lo que hacen. Finalmente, hechas estas consideraciones previas recién es posible pensar la organización jurídica, que a su vez necesita de un plano de principios juridicos y otro de normas positivas, todo desde luego buscando la unidad del sistema como tantas veces lo hemos mencionado anteriormente. Un puro practicismo sólo conduce a soluciones híbridas, ineficaces desde el momento en que fueron formuladas.

Llegamos por último a la parte tal vez más difícil de este estudio. ¿Cómo sentar las bases de una revisión del Derecho? Por supuesto está lejos de nuestra intención presentar un panorama acabado por cuanto ello en verdad es imposible, dado que muchas escuelas de estudiosos lo intenta en nuestros dias y con resultados simplemente parciales, nunca definitivos; con mucho es un problema que requiere un mayor tiempo de maduración. Nuestro intento es modesto pues se limita a algunas consideraciones que pueden servir de motivos de reflexión y no más.

La primera consideración que deseamos hacer se refiere al carácter del Derecho. Al comienzo de nuestro trabajo lo calificamos como poseedor de una tendencia conservadora (entendiendo bien el sentido de la palabra, nunca como una calificación peyorati- 
va que señala una actitud retrógrada) por razones perfectamente justificables. Frente a la necesidad de transformación del Derecho, se plantea la necesidad de un cambio de perspectiva; no defendemos la anulación de esta tendencia conservadora porque señala valores ciertos, sino la apertura de otra orientación que llamaremos prospectiva. Significa este calificativo que el Derecho no solamente debe tender a mantener una paz social o el imperio de la justicia, sino que debe proyectarse hacia los futuros cambios que se pueden auscultar en la sociedad humana. En este sentido bien se puede hablar de una técnica de transformación de carácter jurídico. Hasta el presente los cambios sociales se producen con mucho adelanto a las consideraciones juridicas, las cuales por lo común actúan a posteriori. Cabe pensar entonces en una actitud de presentir el cambio social y adelantar la normatividad jurídica para encauzar la situación que está en proceso de realización.

Las consideraciones anteriores resisten la objeción de que los cambios sociales futuros son imprevisibles y que por tanto el Derecho prospectivo caería en un simple campo de ciencia-ficción. Hoy en día los cambios sociales han dejado de ser espontáneos para convertirse en intencionales. Cuando se escucha hablar de revolución social se está precisamente en esta situación. La tarea del nuevo Derecho como muchos la han comenzado ya, reside pues en pensar el Derecho que se precisa para la futura sociedad ya transformada, lo cual permite a su vez poseer un modelo al cual apuntar. Pero esta perspectiva no se agota aquí, cabe preguntarse lo siguiente ¿no existirá un Derecho que norme las transformaciones sociales mismas? No estamos hablando en este momento del modelo jurídico de la futura sociedad, sino de normas jurídicas aplicables al proceso mismo de transformación. Es claro que dentro de este proceso hay conflictos de intereses, caducidad de derechos antiguos, expropiaciones, crisis, situaciones todas que presentan problemas de interacción humana. Allí cabe hablar de un Derecho. ¿Qué puede hacerse y qué debe no hacerse? Se podría objetar que una situación de cambio es por esencia inestable y que por ello no cabe pensar en derechos, pero podemos pensar también que no todos los cambios son violentamente revolucionarios y que estos procesos que bien pueden ser calificados de estados transitorios, son por ello capaces de ser normados jurídicamente, aún con normas de derecho positivo. Pero aún en casos de una revolución violenta por completo, el Derecho puede ac- tuar aunque ya no desde el ángulo del derecho positivo, pues cabe declarar ciertos principios jurídicos que es necesario respetar incluso para que la revolución pueda ser efectiva y no caótica.

Todo lo que hemos dicho implica tal vez nuevas direcciones en la investigación, pues por ejemplo el jurista tendrá que partir muchas veces de un descontento substancial ante el orden social y jurídico imperante (es claro que ésta es fundamentalmente una labor de investigador, pero que no excluye al juez quien en las legislaciones positivas cada vez en mayor grado, tiene el poder de crear derecho de alguna manera), lo cual lo llevará a pensar en modelos que rectifiquen las situaciones que deben ser superadas. Pero aquí nace la pregunta capital que puede guiarnos en la búsqueda de los principios directrices de la nueva investigación jurídica: ¿cuál es el fundamento principal de esta investigación? Consideramos nosotros que reside como ya dijimos en una concepción del hombre. Para comprender este punto no olvidemos el plano en que nos hemos situado, y es éste el correspondiente a la Filosofía del Derecho; desde esta perspectiva enlaza con la Antropología Filosófica. El Derecho como todas las demás ciencias sociales, puede también ser llamado ciencia del hombre, pues sin lugar a duda que él constituye la base fundamental. La Antropología Filosófica, nacida de la urgencia contemporánea de autocomprenderse que sienten los seres humanos, profundiza el sentido de la humanidad y por esta senda ha logrado comprobar que nuestra noción de hombre actual, si bien problemática y oscura en muchos aspectos, se ha enriquecido en cuanto a sus necesidades y fines por alcanzar. La compenetración de estas dos ramas del saber, Antropología Filosófica y Filosofía del Derecho, han de constituir un matrimonio fecundo en nuevas concepciones. Tal vez todo estudioso de la Filosofía del Derecho precise conocer cuáles son las actuales ideas que sobre el hombre se tienen para poder renovar la investigación del Derecho. ¿Qué aportes podrian señalarse al respecto? Detengámonos un momento en este punto.

La situación concreta y real del hombre aparece como una situación enajenada, tanto por lo caótico de la actual cultura como por la injusticia y, tema que nos toca directamente, el subdesarrollo. La Antropología Filosófica descubre esta situación y la entrega a las ciencias para su solución. El Derecho tiene que enfrentar (desde el nivel en que nos hemos 
colocado en este artículo) la tarea de un proceso que suprima esa alienación que impide que el hombre sea efectivamente un ser humano. Si tomamos aquí el tema del subdesarrollo, la tarea es más clara ¿qué organización juridica contribuye a superar esta situación? Recordemos que muchas críticas a nuestro Código Civil inciden en su orientación marcadamente individualista y resulta que los esfuerzos para evadir el subdesarrollo se orientan hacia una labor cada vez más socializante, ¿puede entonces nuestro Código Civil encajar dentro de esta nueva perspectiva y des-enajenar a nuestro pueblo? La respuesta no puede venir sin un estudio previo.

Otra dimensión del hombre radica en su aspecto social, el "para otro" o como dicen algunos personalistas, "el ser con otro". El Derecho tiene que abordar este tema que recién se halla en sus inicios pues hasta el Derecho Soviético no incorpora del todo esta orientación. Una lectura de la Constitución Soviética y aún de la correspondiente a China Comunista, descubren algo no siempre esperado: que muchos elementos de sus articulados son todavía individualistas (por ejemplo sostienen que cada persona debe poseer una casa, un automóvil y una cuenta en un banco...), es pues evidente que esta dimensión humana está en sus comienzos en cuanto a incorporación a la doctrina jurídica. Conviene mostrar un ejemplo en este punto, y escogemos el caso de la llamada "empresa comunitaria de producción". Es éste uno de los puntos socializantes del personalismo donde se sostiene que toda empresa de producción comercial o no, debe ser una obra de una comunidad de trabajadores, gerentes, capitalistas, sin que ningún grupo tenga prerrogativa alguna y la obra final resulte de un esfuerzo conjunto de todos. El sentido de esta institución no ha sido comprendido del todo pues recordamos un proyecto de ley presentado a nuestro fenecido Parlamento donde dicha forma de empresa se convertía en una simple cooperativa, y lo que era más grave, constituía una forma voluntaria de asociación cuando en el fondo lo que se requería era una forma única de empresa de producción. Es además este caso un ejemplo de cómo una institución inspirada en postulados diferentes a los de un sistema jurídico concreto, se deforma y termina por aceptar una modificación ajena a su naturaleza.

Esta dimensión social ha permitido una ampliación enorme de las funciones del estado, pues no sólo es ahora un protector de los derechos individuales sino que es promotor económico y social, organizador activo de toda la vida nacional hasta los límites del intervencionismo. ¿Podemos hablar aún del "Estado de Derecho"? Ahora tendría un sentido muy diferente al que se le solía aplicar, el cual llevaba una connotación liberal: cada uno puede exigir sus derechos pues están protegidos por el estado. Pero en un estado que acepta la condición social del hombre, evidentemente que no puede limitarse a ser un protector de derechos individuales sino que deberá llegar a los sociales. Aquí otra aclaración; hablar de derechos sociales suena a protección del salario del trabajador y a indemnización por tiempos de servicio, pero esa expresión tiene un sentido muy diferente. Derechos sociales son los correspondientes a la sociedad, sea ésta el estado o las sociedades intermedias (sindicatos, asociaciones de profesionales). ¿Tenemos un derecho organizado con principios y métodos para desarrollar esta vertiente humana? Hasta ahora han sido considerados con un matiz individualista que va poco con el carácter social. Este es un punto clave del "nuevo derecho".

Podríamos hablar en este aspecto de un derecho tridimensional: los derechos del individuo, los derechos del grupo intermedio, y finalmente los derechos de la sociedad como tal. En este último punto se abre una doble perspectiva pues tenemos la sociedad nacional y la internacional. Por supuesto que no hablamos del antiguo Derecho Internacional en el último caso, que en el fondo se limita a normar simples relaciones entre estados independientes, sino que cabe una consideración distinta: hay una sociedad total humana, la cual no puede reconocer sistemas jurídicos diferentes ni límites de fronteras. Hay aquí un asomo del derecho de gentes de Grocio.

En conclusión final, el nuevo derecho debe estar fuertemente unido a las nuevas concepciones del hombre, no por una simple y transitoria moda sino para descubrir en ellas lo fundamental que debe ser normado por las relaciones jurídicas. Hoy tenemos nuevos fines y nuevas necesidades humanas que lógicamente requieren ser aceptados y protegidos para una mejor realización del hombre en cuanto ser humano. Estas consideraciones permiten visualizar el Derecho como vinculado al desarrollo humano en todos sus aspectos, claro que no faltará quien diga que ésta ha sido una orientación permanente del Derecho, pero en verdad no en la forma como es considerado el desarrollo hoy en día: apuntando al futuro y rea- 
lizado por todo el grupo social y no por individualidades; indudablemente que se está ante una perspectiva diferente. Es el carácter prospectivo de que hablábamos. Dentro de este desarrollo humano, el Derecho tiene la finalidad de lograr una cooperación pacifica de todos, salvando resistencias y obstáculos. Debe proporcionar los moldes según los cuales la cooperación pueda ser exigida y realizarse dentro de lo justo. Así se puede conseguir un equilibrio tanto en los momentos de crisis del desarrollo como en la futura sociedad. Equilibrio pacífico de desarrollo humano parece ser la meta del nuevo Derecho.

Por último, toda esta tarea prospectiva del nuevo derecho exige un complemento final: un criterio de juicio sobre sus logros. Este es un tema que pertenece exclusivamente a la Filosofía del Derecho, la cual se convierte asi en un instrumento de análisis sumamente precioso, pero en verdad el camino sólo está por comenzar. ¿Cuáles son los criterios suficientes a tal empresa? Creemos que en este punto la reflexión axiológica se vuelve fundamental. Con todo es necesario hacer aclaraciones pues hablar de axiología para muchos implica referencias a Scheler a quien ya se le considera algo superado. En verdad una axiología si bien reconoce su deuda con este pensador, no tiene por qué enmarcarse dentro de sus moldes de pensamiento. Cabe pensar en una axiología específicamente jurídica como lo postula Bogolini por ejemplo. Esta es una forma de superar el simple positivismo o el mero cientifismo. Un marxista sostendrá que el derecho científico de occidente cae en los negros lindes del idealismo y hablará de reemplazarlo por un derecho revolucionario, pero ¿qué significa esta nueva concepción del derecho? Opinamos que simplemente es la introducción de otros fines dentro de la ciencia jurídica, y si mencionamos fines estamos hablando sin darnos cuenta de valores. Quizá ésta es la diferencia que marca la distinción entre tantos sistemas juridicos: la estimativa que yace tras del aparato conceptual o científico. Pero también la axiología requiere una renovación dentro de lo jurídico, desde luego que no estamos sosteniendo una negación de todo trabajo anterior sino postulando que la realidad humana, base de lo jurídico, ha sufrido un enriquecimiento que es preciso reconocer. 